medicine, and partly in connection with the psychology of the criminal. Lacassagne, in dealing with the subject under this latter aspect, distinguishes three varieties of mutilation, viz., the religious or sacrificial, the judicial, and the criminal ; and Nina Rodriguez has further divided the criminal variety into two main forms-the offensive and the defensive, the former being a mere mutilation for the satisfaction of feelings of hate or in obedience to morbid sexual impulses, while the defensive form is an attempt on the part of the criminal to avoid detection. The practical interest of this distinction is that in the offensive form of criminal mutilation the murderer is always insane, epileptic, or very degenerate, but in the defensive form he may be, and frequently is, relatively normal. The case reported in this paper is given by the author as an illustration of the defensive form. A servant girl, having strangled her newly born child, dismembered the body and put the pieces down a latrine. The way in which the body was cut up, as shown in a photograph of the pieces, resembled in several respects the method followed by cooks in preparing fowls and other animals for the table. This mode of dismemberment, which has been noted in several cases of criminal mutilation, has been termed by Lacassagne "le procédé de la cuisinitere"; it is usually indicative of the defensive form. In this particular case, the point was of interest, because it had been suggested in defence of the accused girl that the mutilation of the body was evidence of a delirious condition with homicidal and destructive impulses at the confinement, it being further asserted that the girl was predisposed to such impulses by the fact of being weak-minded. The author maintains in opposition to this view that the culprit did not present any of the somatic, functional, or psychic anomalies which, according to the Italian school, are distinctive of the criminal degenerate, and he finds this negative evidence in harmony with the defensive character of the mutilation. He further points out that this case illustrates the fact, specially emphasised by Lombroso, that infanticides rarely belong to the congenital criminal class, because in this form of crime the social are much more important than the anthropological factors.

W. C. Sullivan.

\title{
Notes and Nows.
}

\section{THE MEDICO.PSYCHOLOGICAL ASSOCIATION OF GREAT BRITAIN AND IRELAND.}

The Quarterly Megting of the Association was, by the courtesy of Dr. Edwin Goodall and the Committee of Visitors, held at the Cardiff City Mental Hospital on Thursday, February 23rd, 1911. The President of the Association, Dr. John Macpherson, occupied the Chair.

Present: The President and the following forty-three members : Drs. H. Baird, J. V. Blachford, C. Hubert Bond, E. M. P. Braine-Hartnell, F. St]. Bullen, James Chambers, L. F. Cox, M. A. Collins, W. Cotton, T. Drapes, J. F. Dixon, J. E. M. Finch, E. Faulks, E. Goodall, J. W. Geddes, John R. Lord, N. Lavers, J. McGregor, C. Mercier, A. Miller, H.C. McBryan, C.S. Morrison, H. Hayes Newington, Bedford 
Pierce, J. P. P. Phillips, W. A. Parker, N. R. Phillips, D. F. Rambaut, J. M. Rutherford, John Richards, Rothsay C. Stewart, G. E. Shuttleworth, J. G. Soutar, R. J. Stilwell, B. H. Shaw, J. E. P. Shera, W. H. B. Stoddart, G. H. Savage, R. Percy Smith, James Scott, T. Seymour Tuke, J. D. Thomas, and F. Barton White.

Regrets at inability to be present were received from Drs. Bowrer, Clouston, Robert Jones, Monnington, Nolan, Briscoe, Hotchkis, Bevan-Lewis, Oswald, Wolseley-Lewis, and others.

Visitors: Alderman $\mathrm{Ch}$. H. Bird (Lord Mayor of Cardiff), J. T. Richards (Deputy ditto), Alderman Morgan Thomas (Chairman Mental Hospital Committee), Mr. C. F. Sanders (Deputy ditto), Mr. John J. Jackson (Director of Education, Cardiff), Mr. W. C. Clifford Smith (Asylums Engineer, L.C.C.), Mr. R. L. Mackenzie Wallis, Drs. E. Tennison Collins, H. A. Schölberg, James Robinson, J.P., R. J. Smith, J. J. E. Beggs, E. Walford (M.O.H.), W. Sheen, W. Mitchell Stevens, E. J. MacLean, R. V. Stanford, and several others.

Council attendance: There had been present at the previous Council meeting: The President, and Drs. Bond, Chambers, Dixon, Drapes, Hayes Newington, Shuttleworth, Percy Smith, Soutar, and Stoddart.

Prior to the afternoon meeting full advantage was taken of the opportunity to inspect the Mental Hospital.

\section{LUNCHEON.}

By the kindness of the Lord Mayor, the members were entertained at luncheon in the large hall of the hospital. After a generous repast, to the accompaniment of the strains of a string band, some toasts were honoured.

\section{Tonsts.}

The LORD MAYor proposed "The King" in a few graceful phrases, and it was loyally honoured.

The LORD MAYOR then submitted the toast, "The Medico-Psychological Association of Great Britain and Ireland," coupled with the name of its President, Dr. John Macpherson. He said the Association was probably the largest society of medical specialists in the Kingdom, numbering, as it did, about 700 members. Its special function was to watch over the interests of the insane from a medical and scientific standpoint. In the Association practically all medical men engaged in asylums, both public and private, were included, and the Consultants in Lunacy belonged to it. Also, there were many foreign honorary members. The fournat of Mental Science was its organ, and contained many valuable contributions to medical literature. The Association was important in that it granted certificates in mental disorders to medical men who passed its examinations, and it had enormously raised the status of mental nurses. By its system of training and examining mental nurses it had done much for the profession. He was sure the members of their own City Council, who acted on the Committee of the Mental Hospital, would appreciate the advantage of that particular branch of their work. He understood that the Association met only once a year in the country, and the visit to Cardiff therefore showed that its members were particularly interested in the mental hospital of that city. Cardiff had not only the honour of the presence of the members of the Association, of the President and President-Elect, but also other eminent specialists in mental study. For instance, there was Dr. Savage, Consulting Physician in Mental Diseases to Guy's Hospital, and Dr. Charles A. Mercier, Lecturer on Mental Diseases at Charing Cross Hospital. He would like to say a word about the Cardiff Mental Hospital, and to express the hope that its arrangements and organisation would meet with the approval of the members of the Association-men who were particularly qualified to form an opinion on such an important question. He also hoped that the work which the Association would do at Cardiff would be highly interesting to its members, and that their visit to the city would be a pleasant one. It was his pleasure to extend to the Association, on behalf of the city and the members of the City Council, a very hearty welcome. He asked the company to drink to the prosperity of the Association, coupled with the name of Dr. John Macpherson, the President. 
Dr. John Macphrrson, President, responded. He said that, in the name of the Medico-Psychological Association, he desired to express its thanks for the very kindly way in which the Lord Mayor had referred to the members, and to thank the Lord Mayor and the members of the committee for the opportunity afforded of visiting the hospital. He noticed that in their enlightened policy they had dropped the use of the word "asylum." The hospital was well known beyond the bounds of the Principality. He had not yet had the opportunity of seeing it all, but he had seen a good portion of it; and he might say that, speaking generally, they were much impressed with the thoughtful care and wisdom which were displayed in its construction, as well as with the enlightened sympathy which prompted the city to erect an institution so well fitted and so generously adapted to the great purpose it had to subserve. He wished to pay a special tribute to the extraordinary foresight and liberality which led them to establish such magnificent laboratories, and to start them with men who were so capable of utilising them to the best ends. The members of the Association recognised, perhaps better than most people, that an institution of that kind was not completed without a great deal of thought, nor, perhaps, without much animated discussion. But it stood to-day an ornament to the city, and a monument to its public spirit. He believed that the readiest test of the civilisation of any community was the way in which it provided for its insane. Its medical superintendent, Dr. Goodall, was well known in the Association, of which he was an honoured member. His reputation for ability, his intense devotion to that special work in which he was engaged, and his scientific attainments, made the members of the Association more anxious, if that were possible, to see an institution with which his name had become identified. When he said that they were grateful for the opportunity of visiting the institution, he wished it to be understood that he was not simply using a formal polite phrase. For all the kindness which was being shown to the members, he feared they could offer but a very inadequate return, and could only tender their thanks. But he reminded the company that many of those present had travelled long distances to get there, and that among the attributes of that city, accessibility did not rank first. It might perhaps be thought that such a remark came badly from one who hailed from North of the Tweed, but that was a question of where one chose to fix one's centre. There were present gentlemen from England and from Ireland as well as Scotland, which proved that Cardiff had become a sufficiently attractive centre to overcome the mere inconveniences of travel. The Medico-Psychological Association was a society of those whose lifework consisted in the care and treatment of the insane. In pursuance of that object they found it necessary to educate themselves, to keep themselves cognisant of the many changes which distinguished workers, both lay and medical, were constantly introducing throughout the country. That was the principal object of the visit of the Association to Cardiff, and he hoped he had made it clear that the Association had already abundantly profited. If the Association's visit should have the effect of encouraging the authorities at the hospital and of strengthening their hands in any way he would be glad, for if they did not need comfort of that kind they were indeed fortunate. In conclusion, the Association wished them God-speed in the great work they were doing. Members would carry away with them a very pleasant memory of the day's visit, and he assured them that they would go away encouraged in their own special work by the truly educative advancements they had been privileged to see.

Dr. Macpherson proposed "The Lord Mayor and Corporation of Cardiff." In doing so he said there was only one feature upon which they, as members of the Association, were competent to express a sound opinion, namely, the extraordinarily fine mental hospital which they had built. If the Corporation approached all their ordinary undertakings with the same enlightenment and the same ideals as they had shown in connection with the construction of that great hospital, they were indeed worthy of the best recognition and emulation. He coupled the toast with the name of the Lord Mayor.

The LORD MAYOR, in reply, said he felt it a great honour to hear the toast of the Lord Mayor and Corporation of Cardiff proposed by a gentleman of the position of Dr. Macpherson. To those who were not members of the Association, but who were members of the Corporation, he would remark that Dr. Macpherson held a very important position in Scotland, being one of His Majesty's Com- 
missioners in Lunacy-a position of the very highest importance in that connection. In addition there were present some of the most eminent men in that class of study. They in Cardiff had had several things in mind when building the hospital. They desired to put up a building which would be worthy of both the cause and the city; they desired to construct a place in which the patients could be properly housed and cared for, and in which there would be a fair amount of success in curing patients. That fair amount of success, he was pleased to say, had been attained. But they also desired, by the aid of its very efficient staff, headed by Dr. Goodall, to make the hospital a centre in which some investigation and some advancement might be carried out in the interests of that important science. And they were not without hope, nor without reason in hoping, that they would succeed in that direction. In fact they had already, by the help of their experts, made some distinct advances in certain directions. He felt that the visit of an Association such as this was just the thing required as an incentive not only to their own staff-if they felt the need of such an incentive-but also for the encouragement of the people in the city, their own ratepayers, who perhaps from time to time felt critical about the spending of the ratepayers' money on buildings of the kind. It was one of the most important works which thè city had carried on.

Alderman Morgan Thomas, J.P., proposed the toast of "The Visitors," coupled with the names of three eminent gentlemen-Dr. Savage, Dr. Mercier, and Dr. Tenison Collins. After remarking on the honour he felt at having the toast to propose he said Dr. Savage was known for his mental science attainments, not only in Great Britain, but throughout the world. He was sure the company would be pleased to know that among the many students who had sat at the feet of Dr. Savage during the past forty years, Dr. Goodall was one of those fortunate ones who had his first training with him. In Dr. Goodall the hospital had a gentleman of eminent standing, and, speaking on behalf of his Committee and the Corporation, they were highly gratified by the intense interest he had taken in the institution from its inception, and also for his unflagging desire not only to give an adequate return to the ratepayers of the city for its outlay at the hospital, but, above all, to do what he could to cure the unfortunate patients. He was sure all would agree that Dr. Savage had done them a distinct honour in coming to join their festive board on that occasion. Dr. Mercier was also a gentleman who occupied a very high position. There was also present $\mathrm{Dr}$. Tenison Collins, one of their own medical staff, who, he was proud to say, had given considerable assistance to Dr. Goodall with regard to the medical side of the institution. He would like to tell members of the Association that the members of the Visiting Committee, also the members of the Corporation who had supported them in their demands upon the funds, that they had realised that the old idea of asylum work was fast fading away, the old heathenish methods and the belief that when anyone was unfortunate enough to come into such an institution it was "all up" with them, and that there was no hope. He thought he could venture to say, even in the ear of so many critics, that he held that any trouble of the mental faculties was as capable of being cured-provided it was not chronic-as any diseases of the body. He remembered that when the institution was being opened there was considerable discussion as to what it should be called. Some people thought the name should be the Cardiff City Asylum; others thought it should be called a hospital, and the latter was the view which was taken by the Medical Superintendent, who said, "I hold that this should be called a hospital, because we do not do our duty unless we do our best, not to detain people, but to cure them." That was the policy which they were doing their best, however imperfectly at times, to carry out in regard to the administration of the hospital.

The toast was pledged with great heartiness.

Dr. SAVAGB, in responding, expressed his surprise at being chosen, as he expected to have to speak at the dinner in the evening, so that these few remarks must be considered as the prologue, and the speech of Dr. Mercier as the epilogue. About four days ago he was called to his telephone. "Who are you ?" "Evening ." "What do you want ?" "Something about the new cure of insanity."

"There is nothing new under the sun." There was another person at the telephone. "Who are you ?" "Daily _. Do you know anything about burying alive?"

"No personal experience." In replying for the Visitors, he remarked that residents 
in the Metropolis were apt to think that all the brilliancy was there. But there were other sources of light and illumination which did credit to the provinces more than to those in London. In fact it was good for London residents to realise that the work being done in the provinces was as good as could be done anywhere. The work being done at that hospital was astonishingly good. When he was Head of Bethlem they took selected cases, and if there were 30 to 40 per cent. of cures they considered they were doing well. But Cardiff was doing better than that.

Dr. Mercier also responded. He said when he received the imposing invitation from the Lord Mayor he was particularly impressed by the coat-of-arms which appeared at the head. Its impressiveness was coupled with certain misgivings as to the fare that would be set before him. The dexter supporter was a goat, and he remembered the spurious venison which so deceived the Patriarch, and the other animal appeared to be a dragon-he did not know whether he diagnosed it rightly-and he did not know whether he might be regaled upon puddings made of dragon's blood. The company could therefore imagine how his misgivings melted into relief, and his relief into satisfaction, and how his satisfaction rapidly rose into ecstasy upon discovering the nature of the fare. There was one element in the coat-of-arms which still gave rise in his mind to a little uncertainty; he referred to that vegetable esculent, which was, he understood, so wholesome, so desirable, but yet so unattractive, that its cultivators were, according to Shakespeare in the habit of forcing it down the throats of their guests at the point of the sword. He went on to give humorous surmises of the reasons actuating the choice of the various flowers as national emblems, and asked what could have induced Wales to choose the leek.

Dr. Tenison Collins also replied.

\section{Minutes.}

The PResident reminded members that the minutes of the last meeting had already been published in the Journal, and that it was usual to take them as read. This was agreed to, and they were duly signed by the President.

\section{Business Arising from the Council Meeting.}

The President said there were two items arising out of the Council meeting which he would like to refer to. Dr. Oswald, of Glasgow, had written to the Council a letter having reference to the publication in the English press of certain details of a speech which he delivered in Glasgow, and which was misreported. Dr. Oswald desired to state that his remarks were not such as appeared in the public press. The other question he wished to mention was that it was thought the Association should send a deputation to the Home Office with regard to the introduction of a bill on the lines of the Departmental Committee upon Inebriety, for the purpose of urging the Home Secretary to introduce such a bill. The Council had recommended that a deputation from the Association, conjointly with deputations from other public bodies, should ask for an interview with the Home Secretary on that important question. He would like to ask that meeting of members whether that suggestion met with approval.

This was agreed to.

The next business was the election of candidates for ordinary membership. The following gentlemen were unanimously elected:

Cox, Donald Maxwell, M.R.C.S., L.R.C.P.Lond., House Physician, Bethlem Royal Hospital, London, S.E. (Proposed by W. H. B. Stoddart, J. G. Porter Phillips, and C. Hubert Bond.)

Heasman, Herbert Wilks, M.R.C.S., L.R.C.P.Lond., House Physician, Bethlem Royal Hospital, London, S.E. (Proposed by W. H. B. Stoddart, J. G. Porter Phillips, and C. Hubert Bond.)

Kerr, James, M.A., M.D., B.C., D.P.H.Cantab. (Medical Officer of the Educational Committee, L.C.C.), 15, Hanger Lane, Ealing, W. (Proposed by G. E. Shuttleworth, H. Hayes Newington, and G. F. Barham.)

Reeve, Ernest Frederick, M.B., B.S.Lond., M.R.C.S., L.R.C.P., Senior Assistant Medical Officer, County Asylum, Rainhill, Lancs. (Proposed by J. Wiglesworth, Geo. A. Watson, and C. Hubert Bond.) 


\section{INSPECTORSHIP OF LUNATICS rOR IRELAND.}

The President intimated that the Irish Division of the Medico-Psychological Association passed a resolution, on a recent date, that in regard to the appointment of an inspector of lunatics for Ireland, which was now imminent, that the Chief Secretary and the Lord Lieutenant should be urged to appoint to that position someone who had had experience in the treatment of the insane and in their care, as well as in the administration of asylums. The Council that day endorsed that resolution of the Irish Division. And, in order to give to that recommendation greater power, he wished to ask whether the present meeting approved of the action of the Council on the matter.

This was agreed to without dissent.

Dr. H. H. Schölberg and Dr. Edwin Goodall (of the Cardiff Mental Hospital) contributed a paper on "The Wassermann Reaction in 172 Cases of Mental Disorder (Cardiff Mental Hospital), and 55 other cases (Cardiff Infirmary, etc.), with Historical Survey." It was discussed by the President, Dr. W. A. Parker, Dr. G. H. Savage, Dr. Percy Suith, Dr. Faulks, and the readers briefly replied.

Dr. R. V. Stanrord read a paper on "The Production of Indigo in the Human Organism." Remarks on it were offered by Dr. Savage and Dr. Goodall.

Dr. E. Trenison Collins contributed a paper on "Notes on Gynzecological Conditions coincident with Mental Disturbances." Dr. SAVAGE, in the temporary absence of the Chairman, presided, and expressed his regret that the flight of time prevented a discussion.

Mr. R. L. MACKEnZie-WAlL Is communicated a contribution on "Metabolism in the Insane." The time-limit also prevented the discussion of this paper.

DINNER.

In the evening the members, with the Lord Mayor, Alderman Morgan Thomas, J.P., and a number of distinguished medica' and lay visitors, dined together at the Royal Hotel, Cardiff.

After the usual loyal toasts had been duly honoured, the Chairman proposed "The City and Port of Cardiff." The LoRd MAYOR responded. Dr. SAvage proposed "The Mental Hospital Committee," which was responded to by Alderman Morgan Thomas and Dr. Goodall. The toast of "The Visitors" was proposed by Dr. Mercier, and Dr. Ewan Maclean replied. "The MedicoPsychological Association" was the last toast, proposed by Mr. SHeEn, and replied to by the President.

During the evening some songs were very tastefully rendered by Madame HamblySpay and Mr. H. Morgan.

\section{IRISH DIVISION.}

A special meeting of the Division was held, by permission of the President of the Association, on Thursday, February 9th, 1911, at the Royal College of Physicians, Dublin. Dr. T. Drapes, President-Elect, was voted to the chair, and there were also present Drs. James J. Fitzgerald, R. R. Leeper, J. Mills, G. F. Shepherd, G. R. Lawless, H. M. Eustace, and W. R. Dawson, Hon. Sec. Regrets for inability to attend were received from Drs. W. Graham, T. P. Coulon, E. $O^{\prime}$ Neill, and M. J. Nolan.

The subject of the impending vacancy in the office of Inspector of Lunatics was discussed, and in view of the danger that the appointment might be given to someone not an expert in mental disease the following resolution was passed unanimously:

"That the Irish Division of the Medico-Psychological Association would strongly urge on the Irish Members of Parliament the extreme importance, in filling the post about to be vacated by Dr. E. M. Courtenay, Inspector of Lunatics, of selecting a candidate who is specially qualified by actual residence amongst 